\title{
LACTOBACILLUS ACIDOPHILUS-DERIVED BIOSURFACTANT EFFECT ON GTFB AND GTFC EXPRESSION LEVEL IN STREPTOCOCCUS MUTANS BIOFILM CELLS
}

\author{
*Arezoo Tahmourespour ${ }^{1}$, Rasoul Salehi², Rooha Kasra Kermanshahi ${ }^{3}$
}

${ }^{1}$ Assistant Professor of Microbiology, Islamic Azad University-Khorasgan branch, Isfahan, Iran; ${ }^{2}$ Associated Professor of Genetics, Medical School, Isfahan University of Medical Sciences, Isfahan, Iran; ${ }^{3}$ Professor of Microbiology, Alzahra University, Tehran, Iran.

Submitted: January 28, 2010; Returned to authors for corrections: April 23, 2010; Approved: June 21, 2010.

\begin{abstract}
Streptococcus mutans (S. mutans), harboring biofilm formation, considered as a main aetiological factor of dental caries. Gtf genes play an important role in S. mutans biofilm formation. The purpose of this study was to investigate the effect of Lactobacillus acidophilus-derived biosurfactant on S. mutans biofilm formation and $g t f B / C$ expression level (S. mutans standard strain ATCC35668 and isolated S. mutans strain (22) from dental plaque).

The Lactobacillus acidophilus (L. acidophilus) DSM 20079 was selected as a probiotic strain to produce biosurfactant. The FTIR analysis of its biosurfactant showed that it appears to have a protein-like component. Due to the release of such biosurfactants, L. acidophilus was able to interfere in the adhesion and biofilm formation of the S. mutans to glass slide. It also could make streptococcal chains shorter. Using realtime RT-PCR quantitation method made it clear that gtfB and gtfC gene expression were decreased in the presence of L. acidophilus-derived biosurfactant fraction.

Several properties of $S$. mutans cells (the surface properties, biofilm formation, adhesion ability and gene expression) were changed after L. acidophilus- derived biosurfactant treatment. It is also concluded that biosurfacant treatment can provide an optional way to control biofilm development. On the basis of our findings, we can suggest that the prepared biosurfactant may interfere with adhesion processes of $S$. mutans to teeth surfaces, provided additional evaluation produce satisfactory results.
\end{abstract}

Key words: Biofilm formation, biosurfactant, gtfB/C, Lactobacillus acidophilus, real-time RT PCR, Streptococcus mutans

\section{INTRODUCTION}

Streptococcus mutans (S. mutans), harbouring the dental biofilm, is one of the etiological factors of dental caries (16). Its ability to adhere to the teeth surface is vital for the initiation and progression of dental caries $(3,6,31)$. The $S$. mutans adhesion mechanism is related to synthesis of both extracellular enzymes, glucosyl transferase (GTF) and fructosyl transferase (FTF) $(7,17,26)$. These enzymes are responsible for the synthesis of extra cellular polysaccharides such as glucans and

*Corresponding Author. Mailing address: Assistant Professor of Microbiology, Khorasgan Branch, Islamic Azad University, Isfahan, Iran.; Add: no. 21, Sh. Salimian st., Daneshgah Bv., Azadi sq., Isfahan, Iran.; Fax: +98 311 5354061.; E.mail: atahmoures@ @huisf.ac.ir / arezootahmourespour@gmail.com 
fructans. These polymers mediate adherence of $S$. mutans to the tooth surfaces and surfaces of bacteria. They also play an important role in the formation of plaque, the precursor of dental caries $(13,27)$.

$\alpha-(1-3)$ and $\alpha-(1-6)-$ linked glucan polymers are encoded by the genes $g t f B, g t f C$ and $g t f D$. Recently, in vitro studies indicated that $g t f B$ and $g t f C$ are essential for the sucrosedependent attachment of $S$. mutans cells to hard surfaces (2) but gtfD is dispensable $(8,43)$. Therefore, these genes have become a potential target for protection against dental caries (7).

Lactobacilli, as probiotic agents, are believed to interfere with pathogens by different mechanisms $(22,30)$. One of its mechanisms is biosurfactant production.

Biosurfactants, a structurally diverse group of surface active molecules synthesized by microorganisms, have attracted attentions in recent years. Because the reason, they had several advantages on synthetic surfactants, such as low toxicity, inherent good biodegradability and ecological acceptability. Biosurfactants include unique amphipathic properties derived from their complex structures, which include a hydrophilic moiety and a hydrophobic portion (37). The use of biosurfactants from probiotic bacteria as antimicrobial and/or anti-adhesive agents has been studied before and their ability to inhibit adhesion of various microorganisms isolated from explanted voice prostheses has been demonstrated (20).

The present research focused on the influence of Lactobacillus acidophilus (L. acidophilus)-derived biosurfactant on the $g t f B$ and $g t f C$ genes expression level in $S$. mutans biofilm cells by real time RT PCR for the first time.

\section{MATERIALS AND METHODS}

\section{Bacterial strains and culture conditions}

The $S$. mutans strains used in this study were $S$. mutans ATCC35668 and dental plaque isolated S. mutans 22, with high ability of biofilm forming.

S. mutans strains were cultured on blood agar and mitis salivarius agar media and were incubated in a $\mathrm{CO}_{2}$ enriched, 37 ${ }^{\circ} \mathrm{C}$ atmosphere. The identification of strains was done by usual biochemical tests and rapid identification kit of Streptococci (Rap ID STR kit) and by PCR. L. acidophilus DSM 20079 as a probiotic source was cultured in MRS broth or Agar.

\section{Biosurfactant production}

$15 \mathrm{~mL}$ of L. acidophilus cultured overnight was inoculated to $600-\mathrm{ml}$ of MRS broth and incubated for 24 hours. The cells were harvested by centrifugation at $10,000 \times g$ for $5 \mathrm{~min}$ at 10 ${ }^{\circ} \mathrm{C}$, washed twice in demineralized water, and were resuspended in $100 \mathrm{ml}$ of PBS. The lactobacilli were incubated at room temperature for 2 hours with gentle stirring for biosurfactant production.

Subsequently, the bacteria were removed by centrifugation, and the remaining supernatant liquid was filtered through a $0.22 \mathrm{~mm}$-pore-size filter (Millipore). A 10-ml portion of the supernatant was used immediately in the adhesion assay, and the remainder was dialyzed against demineralized water at $4{ }^{\circ} \mathrm{C}$ in a Spectrapor membrane tube (molecular weight cutoff, 6'000 to 8'000; Spectrum Medical Industries, Inc.), and was freezedried as in method of Velraed et al (38).

\section{Drop-collapse method}

In order to test whether produced biosurfactant was able to decrease the surface tension between water and hydrophobic surfaces, the ability to collapse a droplet of water was tested as follows: $25 \mu \mathrm{L}$ of extracted biosurfactant was pipetted as a droplet onto parafilm; the flattening of the droplet and the spreading of the droplet on the parafilm surface was followed over seconds or minutes.

Subsequently, methylene blue (which had no influence on the shape of the droplets) was added to the water stain and supernatants for photographic purposes. The droplet was allowed to dry and the diameter of the dried droplet was recorded $(14,34)$.

\section{Fourier transform infrared spectroscopy}

Freeze-dried biosurfactants $(2 \mathrm{mg}$ ) were ground with $100 \mathrm{mg}$ $\mathrm{KBr}$ and compressed at 7'500 $\mathrm{kg}$ for 3 min to obtain translucent pellets. Infrared absorption spectra were recorded 
with a model (Nicolet Impact 400) instruments (the spectral resolution and wave number accuracy were 4 and $0.01 \mathrm{~cm}^{-1}$, respectively). $\mathrm{KBr}$ pellet was used as the background reference.

Quantity of a spectral region of interest was determined by normalizing the area under the absorption bands regarding to the area of the $\mathrm{CH}$ absorption band around $2^{\prime} 932 \mathrm{~cm}^{-1}(25,38)$.

\section{Biofilm formation assay}

Glass slide method: In order to generate $S$. mutans biofilm on the glass slide, $1 \mathrm{~mL}$ of $S$. mutans over night cultured $\left(10^{8}\right.$ $\mathrm{CFU} / \mathrm{ml}$ ) was inoculated into a flask containing $100 \mathrm{~mL}$ of sterile BHI broth supplemented with $1 \%$ sucrose and two slides with and without L. acidophilus-derived biosurfactant. The glass slides were washed in detergent solution, rinsed in distilled water twice, then air dried and autoclaved at $121{ }^{\circ} \mathrm{C}$ for 15 minutes before use. The flasks were incubated in an orbital incubator $(100 \mathrm{rpm})$ at $35-7{ }^{\circ} \mathrm{C}$ for $18-20 \mathrm{~h}$. Then, the glass slides were removed from the flasks and rinsed twice with $10 \mathrm{ml}$ of PBS solution in order to remove unattached cells. Removed glass slides were stained with $2 \%$ crystal violet for 5 minutes, washed, air dried and photographed under an optical microscope with digital camera (Nicon, Eclipse, E200, Japan)(5).

Microtiter plate method: In order to generate biofilm on microtiter plate wells, $20 \mu \mathrm{L}$ of overnight cultured $S$. mutans was placed in each wells of a 24 wells polystyrene multidishes and was cultivated with $2 \mathrm{~mL}$ of $\mathrm{BHI}$ broth supplemented with $1 \%$ sucrose. The plates were incubated at $37{ }^{\circ} \mathrm{C}$ in an atmosphere enriched with $5 \% \quad \mathrm{CO}_{2}$. After 18 hours of incubation, the spent medium was aspirated and wells were washed with PBS solution in order to remove unattached cells. The biofilm was incubated again in fresh BHI with $1 \%$ sucrose; after another 18-hour incubation, the spent medium was aspirated again. The cells were washed and the biofilm was incubated again in fresh BHI broth with $1 \%$ sucrose supplemented with and without $2.5 \mathrm{mg} / \mathrm{ml}$ of freeze-dried biosurfactant. After 4 hours of incubation, the cells of the biofilms were dislodged into tubes containing $2 \mathrm{~mL}$ PBS solution and vortexed (31).

\section{Extraction of total RNA}

The prepared biofilm cells on microtiter plates (S. mutans ATCC 35668 \& S. mutans 22 with and without biosurfactant, in 3 replicate) were used for RNA extraction. Cells were disrupted using ribolyser instrument (Hybaid, UK.) and the supplied kit according to the manufacturer's instruction in which RNAcontaining supernatant from ribolyser tube was transferred to new RNase free microtube, centrifuged and treated with $300 \mu \mathrm{L}$ of chloroform-isoamyl alcohol, vortexed and centrifuged. Then total RNA was recovered by precipitation with isopropanol and dried under appropriate sterile conditions. Quantitative and qualitative evaluations performed on the extracted RNA by spectrophoto-metrically (biophotometer, Eppendorff, Rs 232-C, Germany) and Agarose-gel electrophoresis.

\section{Reverse transcription}

A reverse transcription (RT) reaction mixture $(20 \mu \mathrm{L})$ containing $50 \mathrm{ng}$ of random hexamers, $2 \mu \mathrm{g}$ of total RNA sample and up to $12 \mu \mathrm{L}$ DEPC-treated water was incubated at $70{ }^{\circ} \mathrm{C}$ for $5 \mathrm{~min}$ to remove any secondary structure and was placed on ice. Then $5 \mathrm{X}$ RT buffer $(4 \mu \mathrm{L}), 20 \mathrm{U} / \mu \mathrm{L}$ Ribonuclease Inhibitor $(1 \mu \mathrm{L})$ and $10 \mathrm{mM}$ dNTPs mix (Cinagen) were added to each reaction mixture, after 5 minutes incubation in $37{ }^{\circ} \mathrm{C}, 1 \mu \mathrm{L}$ reverse transcriptase was added. Then the mixture was incubated at $42{ }^{\circ} \mathrm{C}$ for 60 minutes. The reaction was terminated by heating the mixture at $70{ }^{\circ} \mathrm{C}$ for 10 minutes, and the cDNA samples were stored at $-20{ }^{\circ} \mathrm{C}$ to be used later.

\section{Real-time quantitative RT-PCR}

PCR amplification of synthesized cDNAs were first optimized by conventional PCR. Real time quantitative RTPCR was performed using the ABI-step I (Applied Biosystems, USA) instrument and SYBR Green PCR Master Mix (Qiagene).

The relative quantitation of $g t f B / C$ genes were made against 16s rRNA as a reference gene. All primers and their location summerised in Table 1 (31). 
The reaction mixture $(20 \mu \mathrm{L})$ contained $1 \mathrm{X}$ SYBR Green PCR Master Mix (Qiagene), the appropriate forward, reverse PCR primers $(1 \mu \mathrm{M})$ and $1 \mu \mathrm{L}$ of the cDNA sample. PCR program consisted of an initial denaturation at $95{ }^{\circ} \mathrm{C}$ for 5 minutes, then 40 cycles of amplification applied as follow: denaturation at $95{ }^{\circ} \mathrm{C}$ for 15 second and annealing and extension at $60{ }^{\circ} \mathrm{C}$ for 1 minute. Appropriate negative and positive controls were included. Using the two-step protocol described above, all primer pairs were checked for primer- dimer formation without the addition of template. As an additional control for each primer pair and each RNA sample, the cDNA synthesis reaction was carried out without reverse transcriptase in order to identify whether the RNA samples were contaminated by residual genomic DNA. The critical threshold cycle $(\mathrm{Ct})$ was defined as the cycle in which fluorescence becomes detectable above the background fluorescence and was inversely proportional to the logarithm of the initial number of template molecules.

Table 1. Nucleotide sequences of primers

\begin{tabular}{llll}
\hline Sequence $\left(\mathbf{5}^{\prime}-\mathbf{3}^{\prime}\right)$ & Fragment location & Accession number & Primer \\
\hline$g t f B-\mathrm{F}$ & AGCAATGCAGCCAATCTACAAAT & $1150-1172$ & M17361 \\
$g t f B-\mathrm{R}$ & ACGAACTTTGCCGTTATTGTCA & $1224-1245$ & $\mathrm{M} 17361$ \\
$g t f C-\mathrm{F}$ & CTCAACCAACCGCCACTGTT & $434-453$ & $\mathrm{M} 22054$ \\
$g t f C-\mathrm{R}$ & GGTTTAACGTCAAAATTAGCTGTATTAG & $496-524$ & $\mathrm{M} 22054$ \\
$16 \mathrm{~S}-\mathrm{rRNA}-\mathrm{F}$ & CCTACGGGAGGCAGCAGTAG & $243-262$ & $\mathrm{X} 58303$ \\
$16 \mathrm{~S}-\mathrm{rRNA}-\mathrm{R}$ & CAACAGAGCTTTACGATCCGAAA & $321-343$ & X58303 \\
\hline
\end{tabular}

\section{RESULTS}

\section{Drop collapse assay}

In drop collapse assay, no activity was detected for distilled water as predicted. The biosurfactant droplets do result in a collapsed droplet (Figure 1), indicating their effects on reduction of surface tension.

\section{Fourier transform infrared spectroscopy}

The molecular composition of the biosurfactant used in this study was analysed by Fourier transform infrared spectroscopy (Figure 2). The most important bands were located at $2^{\prime} 933 \mathrm{~cm}^{-1}$ (CH band: $\mathrm{CH} 2-\mathrm{CH} 3$ stretching), 1'653 $\mathrm{cm}^{-1}$ (AmI band: CAO stretching in proteins), $1^{\prime} 480 \mathrm{~cm}^{-1}$ (AmII band: NOH bending in proteins), 1'248 $\mathrm{cm}^{-1}$ (PI band: phosphates), and 1'099 $\mathrm{cm}^{-1}$ (PII band: polysaccharides). Therefore one of the components of $L$. acidophilus DSM 20079 biosurfactants appeared to be protein (Figure 2).

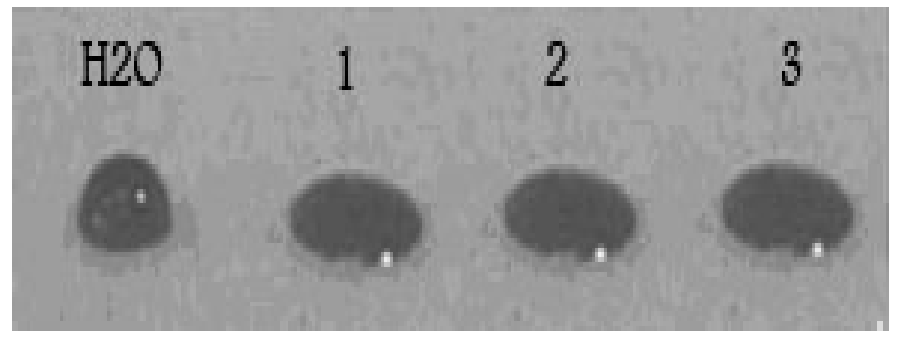

Figure 1. Drop collapse assay. Collapsed droplets (1, 2 \& 3) are the L.acidophilus-derived biosurfactant 


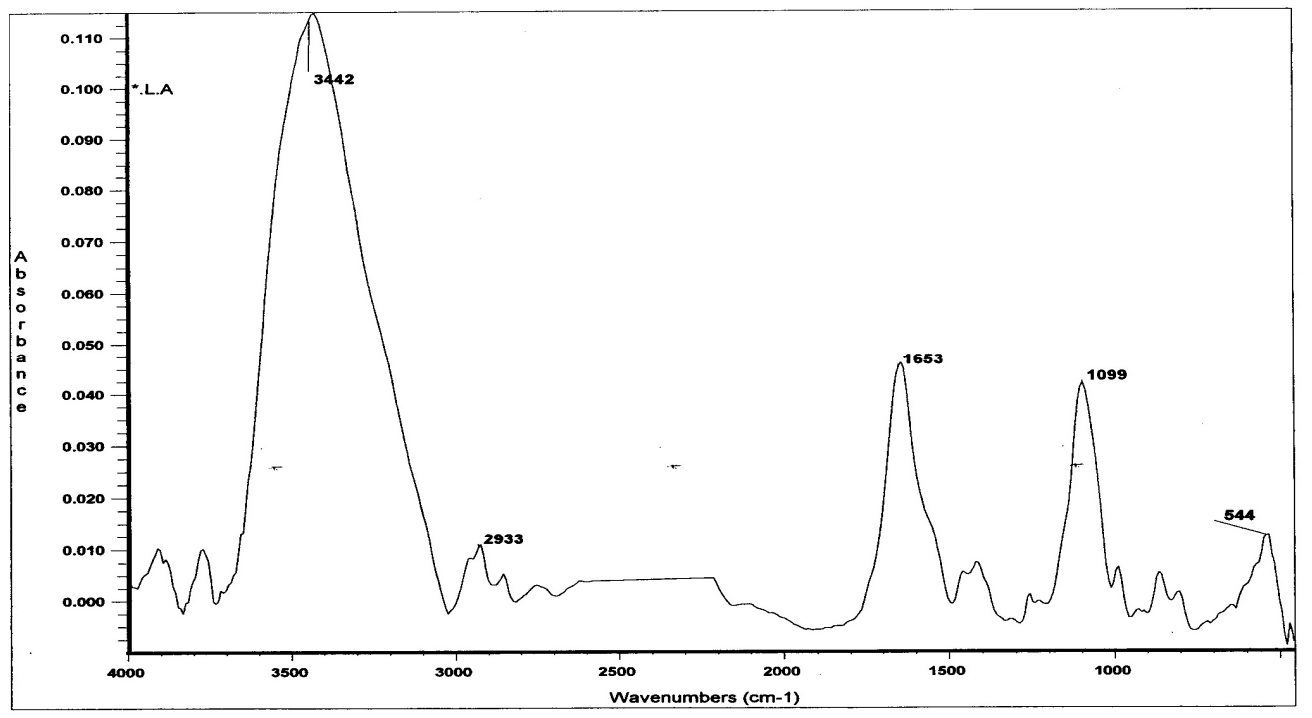

Figure 2. The spectrum of the freeze-dried biosurfactant released from Lactobacillus acidophilus

\section{Biofilm formation}

As it is shown in Figure $3 \mathrm{~A} / \mathrm{B}$, the presence of $2.5 \mathrm{mg} / \mathrm{ml} \mathrm{L}$. acidophilus derived biosurfactant, dramatically reduced the process of attachment and biofilm production .It could also make chain shortening.

The attached bacterial cells were collected from the wells of microtiter plates (Figure 4A) and used for RNA extraction by mentioned method (Figure 4B).

\section{The effect of biosurfactant on $g t f B$ and $g t f C$ expression}

Real-time RT-PCR was used to quantify the effect of $L$. acidophilus-derived biosurfactant on $g t f B$ and $g t f C$ gene expression in biofilm of $S$. mutans ATCC35668 and S. mutans 22 (Figures 5A and B). As an internal reference 16srRNA gene was used.

In the biofilm environment, tested biosurfactant significantly reduced $g t f B$ and $g t f C$ gene expression $(\mathrm{p}<0.05)$. However, the effect of biosurfactant on two genes was not identical with more pronounced gtfB gene expression suppression. Regarding S. mutans 22, the extent of reduction of gtfB expression level was more than the standard strain (p,0.05), but it's effect on gtfC expression level was the same as the standard strain.
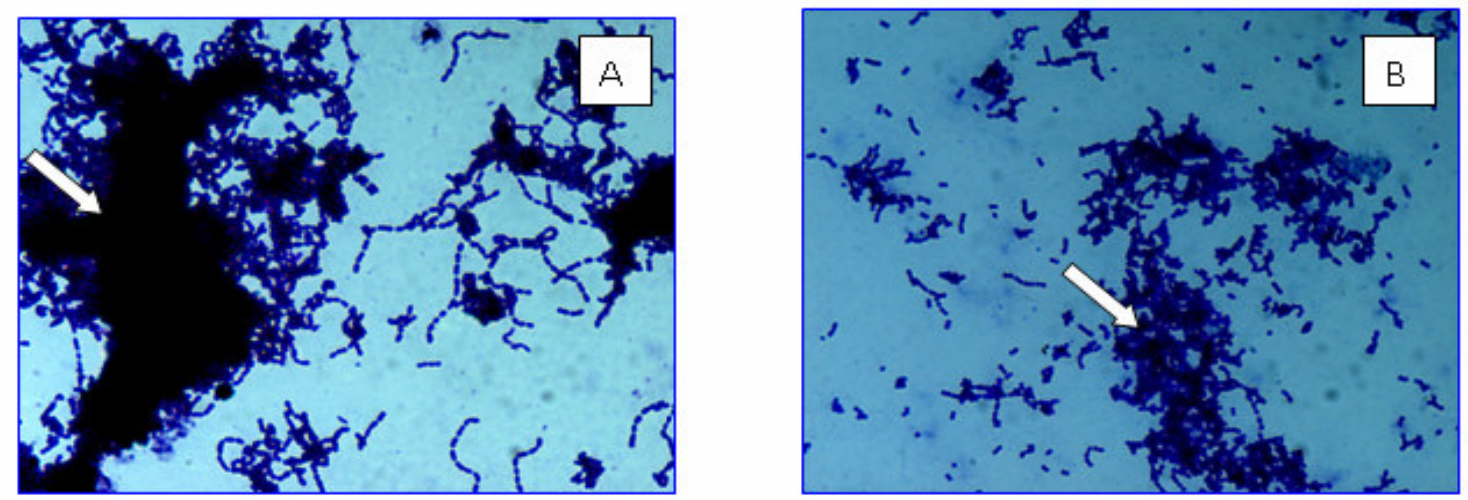

Figure 3. S.mutans biofilm biofilm formation on glass slide. A:control group (in the absence of biosurfactant). B: Experimental group(in the presence of Lactobacillus acidophilus-derived biosurfactant ) (The arrows show depth of biofilm.) 

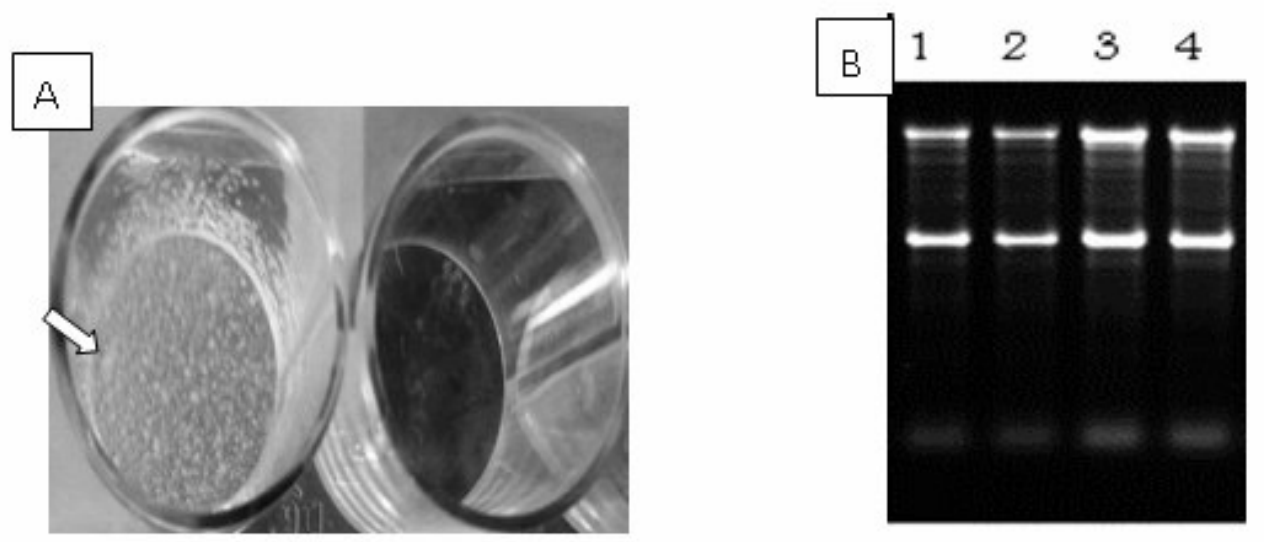

Figure 4. A: Attached cells to PVC microtiter plate well. B: total RNA extracted RNA from biofilm producing cells on PVC micrtiter plate. (lane1,2: Total RNA from S.mutans 22 in the abscence and presence of biosurfactant, respectively. lane 3,4 Total RNA from standard strain in the abscence and presence of biosurfactant, respectively.)
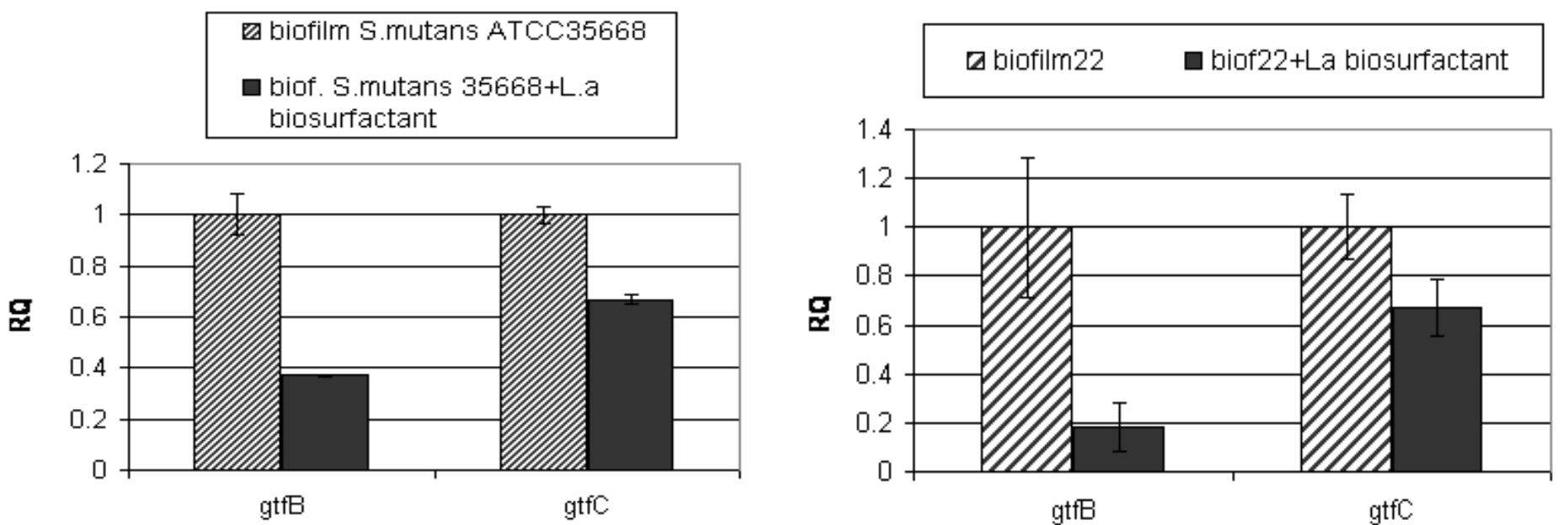

Figure 5. The effect of Lactobacillus acidophilus-derived biosurfactant, on $g t f B / C$ in biofilm immobilized. A: S. mutans ATCC 35668; B: S. mutans 22 (isolated from dental plaque).

The mRNA expression levels were calibrated relative to the control group (in the absence of biosurfactant). The results were expressed as the means and standard errors of dublicate experiments using primers specific for $g t f B / C$ and $16 \mathrm{~S}$ rRNA (normalizing gene).

\section{DISCUSSION}

Oral infection constitute some of the most prevalent and expensive forms of human infection. The disease is widespread in all age groups with least success to control the actual infection. Dental caries is a multi factorial disease tightly related with the presence of cariogenic bacteria, Streptococcus mutans, which are embedded in the dental plaque biofilm.

As $S$. mutans is involved in dental caries, it must be inhibited. Increasing problems of resistance to synthetic antimicrobials have encouraged the researchers to research on alternative natural products (1) such as probiotic bacteria and 
their products.

Some of microorganisms such as lactic acid bacteria were found to be biosurfactant producing strains $(21,25,35,38)$. One of the major roles known for biosurfactants is their negative effect on other microbial species.

In this study, 24-h culture of L. acidophilus was used to release biosurfactant, because Velraed et al. (38) and Rodrigues et al. (21) showed that the 24-h cultures exhibited the largest and most rapid decreases in liquid surface tension.

The biosurfactant activity showed that we had used real surfactant preparations, since the force or interfacial tension between the drop containing the surfactant and the parafilm surface was reduced and resulted in the spread of the drop. Rodrigues et al. (25), Kuiper et al. (14) and Walencka et al. (39) also showed that surface tension was reduced by biosurfactants.

The dialyzed (molecular weight cutoff 6,000 to 8,000) and freeze-dried biosurfactant derived from L. acidophilus DSM20079 was examined by Fourier transform infrared spectroscopy and was compared with the reference compounds albumin, salivary glycoprotein, dextran, lipoteichoic acid and other FTIR spectra of biosurfactants (38).

On the basis of the results, it was concluded that the biosurfactant from $L$. acidophilus had more protein than polysaccharide and phosphate. According to figure 3-A and 3-B, it is also clear that, the biosurfactant could reduce the adhesion of $S$. mutans to glass slide. Velraeds et al. (38) demonstrated that, the biosurfactants from L. acidophilus $\mathrm{RC} 14$ and $L$. fermentum B54 were richer in protein and also contained less polysaccharide and phosphate than the biosurfactants from $L$. casei subsp. rhamnosus 36 and ATCC7469.

Due to the release of such biosurfactant, L. acidophilus could interfere in the adhesion and biofilm formation of the $S$. mutans to glass slide. It also could make streptococcal chains shorter (Figure 3b).

Van Hoogmoed et al. $(10,11)$ reported that, the release of biosurfactant from $S$. mitis BMS could interfere in the adhesion of the cariogenic $S$. mutans to glass in the presence and absence of a salivary conditioning film. Others also confirmed that biosurfactants had inhibitory effect on bacterial adhesion and also biofilm formation $(9,22-25,29)$.

However, the precise mechanisms of such effects have not yet been explained. It seems to be highly dependent on biosurfactant type and the properties of the target bacteria. The simplest way to explain biosurfactant antiadhesion and antibiofilm activities would be their direct antimicrobial action. However, the antimicrobial activity of biosurfactants have not been observed in all cases $(25,39)$.

Thus, Walencka et al. (39) reported that the way in which surfactants influenced bacterial surface interactions appeared to be more closely related to the changes in surface tension and bacterial cell-wall charge. These factors are very important in overcoming the initial electrostatic repulsion barrier between the microorganism cell surface and its substrate. Surfactants may affect both cell-to-cell and cell-to-surface interactions. Their results support the idea that lactobacilli-derived agents remarkably have an effect on these interactions (39).

In this study, we made an effort to investigate the effect of L. acidophilus-derived biosurfactant on $g t f B$ and $g t f C$ genes expression level. The expression of these genes and the production of insoluble extracellular glucans mediate the attachment of $S$. mutans not only to the surfaces but also to other active form of bacteria which are favorable to the organisms for the persistent colonization of tooth surfaces (28).

Additionally, gtf genes are known virulence factors associated with the pathogenesis of dental caries and high content of insoluble glucans in dental plaque which is related to elevated risk of biofilms cariogenicity in humans (19). VaccaSmith et al. (36) mentioned that GtfB levels in saliva were correlated with presence of caries in humans.

Several environmental factors can influence on expression and activity of the GTF enzymes. The existence of various enzymes in the process of carbohydrate metabolism and transport, glucan synthesis and secretion, and degradation in the oral streptococci, in addition to factors that involve posttranslational modifications of the GTF enzymes, have traditionally complicated the understanding of regulatory studies $(4,41)$. 
Multiple regulatory networks that incorporate external signals, such as two-component regulatory systems, are necessary for biofilm formation. S. mutans also possesses a LuxS-mediated signaling pathway that affects biofilm formation. LuxS is the enzyme that catalyzes the reactions leading to the production of the AI-2 signal molecule $(40,42)$. In addition, a number of other gene products, such as BrpA (a cell surface-associated biofilm regulatory protein), have also been shown to play critical roles in environmental stress responses and biofilm development by $S$. mutans $(40,41)$. While much effort has been dedicated to understanding the molecular mechanisms of adherence, biofilm development and virulence gene expression by $S$. mutans in pure cultures, there are large gaps in our knowledge of how this cariogenic bacterium acts in response to inter-generic interactions with bacteria normally found in the supragingival plaque (41).

Our results showed that the L. acidophilus-derived biosurfactant, or a putative signaling molecule in the extract, down regulate the expression level of genes playing important role in the process of $\mathrm{S}$. mutans attachment and biofilm formation.

Clearly, most studies have focused on the production and gene regulation of virulence factors such as GTFs, which play an important role in biofilm formation by $S$. mutans for the purpose of controlling dental caries $(12,32)$.

The ability of $S$. mutans to produce extracellular polysaccharides from dietary carbohydrates has been demonstrated to significantly enhance its cariogenicity. Thus, the less these extracellular polysaccharides produced, the cariogenicity of $S$. mutans can be less.

Tomita et al (33) demonstrated that chemical surfactants exerted different effects on the synthesis of glucosyltransferases in $S$. mutans. So that the presence of Tween 80 in media significantly increased in glucosyltransferases (GTFs), while Triton X-100 decreased it.

These results indicated that several properties of bacterial cells (the surface properties, gene expression, etc) were also changed after biosurfactant treatment. The situation in natural systems is obviously more complex and requires the consideration of many additional parameters $(15,39)$.

In general, biosurfacant treatment can provide an optional way for controlling biofilm development and also influence the adhesion ability of bacterial pathogens (18).

Currently, further investigations are being done in our laboratory on the effect of other probiotic biosurfactant such as L. fermentum and L. rhamnosus on gtfB, gtfC and ftf expression in $S$. mutans biofilm.

\section{REFERENCES}

1. Allakera, R.P.; Douglasb, C.W.I. (2009). Novel anti-microbial therapies for dental plaque-related diseases. Int. J. Antimicrob. Agents. 33, 8-13.

2. Aoki, H.; Shiroza, T.; Hayakawa, M.; Sato, S.; Kuramitsu, H. K. (1986). Cloning of a Streptococcus mutans glucosyltransferase gene coding for insoluble glucan synthesis. Infect. Immun. 53, 587-594.

3. Barbieri, V.A. D.; Vicente, V.A.; Fraiz2, F.C.; Lavoranti, O.J.; Svidzinski, T.I.E.; Pinheiro, R.L.(2007). Analysis of the In Vitro adherence of Streptococcus mutans and Candida albicans. Braz. J. Microbiol. 38, 624-631.

4. Banas, J.A.; Vickerman, M.M. (2003). Glucan binding proteins of the oral streptococci. Cri.t Rev. Oral Biol. Med. 14(2):89-99.

5. Bos, R.; Mei, H.C.; Busscher, H.J. (1999). Physico - chemistry of initial microbial adhesion interactions - its mechanisms and methods for study. FEMS Microbiol. Rev. 23, 179 - 230.

6. Caglar, E.; Kargul, B.; Tanbogaet, I. (2005). Bacteriotherapy and probiotics role on Oral health. Oral Dis. 11, 1-7.

7. Chia, J.S.H.; Teng, T.Y.; Chen, L.J.; Hahn, J.Y.; Yang, L.J. (1991). Glucosyltransferase Gene Polymorphism among Streptococcus mutans Strains. Infect. Immun. 59 (5), 1656-1660.

8. Hanada, N.; Kuramitsu, H. K. (1988). Isolation and characterization of the Streptococcus mutans gtfC gene, coding for synthesis of both soluble and insoluble glucans. Infect. Immun. 56, 1999-2005.

9. Heinemann, C.; Hylckama, J.; Janssen, D.B.; Busscher, H.J. (2000). Purification and characterization of a surface binding protein from Lactobacillus fermentum RC-14 that inhibits adhesion of Enterococcus faecalis 1131. FEMS Microbiol. Lett. 190(1), 177.

10. Hoogmoed, C.G. (2000). Inhibition of S. mutans NS adhesion to glass with and without a salivary conditioning film by biosurfactant releasing S.mitis Strains. Appl. Environ. Microbiol. 66(2), 659-63.

11. Hoogmoed, C.G.; Mei, H.C.; Busscher, H.J. (2004). The influence of biosurfactants released by S.mitis BMS on the adhesion of pioneer Strains and cariogenic bacteria. Biofoul. 26(6), 261-67.

12. Huang, M.; Meng, L.; Fan, M.; Hu, P.; Bian,Zh. (2008). Effect of biofilm formation on virulence factor secretion via the general secretory pathway in Streptococcus mutans. Arch. Oral. Bio. 2118, 
doi:10.1016/j.archoralbio.2008.07.007.

13. Jae-Gyu, J.; Klein, M.I. ; Xiao, J.; Gregoire, S.; Rosalen, P.L.; Koo, H. (2009). Influences of naturally occurring agents in combination with fluoride on gene expression and structural organization of Streptococcus mutans in biofilms. BMC Microbiol. 9, 228-38.

14. Kuiper, I.; Lagendijk, E.L.; Pickford, R.; Derrick, J.P.; Lamers, G.E.M.; Thomas-Oates, J.E.; Lugtenberg, B.J.J.; Bloemberg, G.V. (2004). Characterization of two Pseudomonas putida lipopeptide biosurfactants, putisolvin I and II,which inhibit biofilm formation and break down existing biofilms. Mol. Microbiol. 51(1), 97-113.

15. Mack, D.; Becker, P.; Chatterje, I.; Dobinsky, S.; Knobloch, J.K.M.; Peter, G.; Rohde, H.; Herrmann, M. (2004). Mechanisms of biofilm formation in Staphylococus epidermidis and Staphylococcus aureus: functional molecules, regulatory circuits, and adaptive responses. Inter. $J$. Med. Microbiol. 294, 203-212.

16. Marsh, P. (2003). Are dental diseases examples of ecological catastrophes? Microbiology. 149, 279-94.

17. Moreira, M,; Vicente, V.A.; Glienke, Ch.(2007) Genetic variability of Streptococcus Mutans isolated from low - income families, as shown by RAPD markers. Braz. J. Microbiol. 38:729-735.

18. Ofek, I.; Hasty, D.L.; Sharon, N. (2003). Anti-adhesion therapy of bacterial diseases: prospects and problems. FEMS Immunol. Med. Microbiol. 38,181-191.

19. Paes Leme, A.F.; Koo, H.; Bellato, C.M.; Bedi, G.; Cury, J.A. (2006). The role of sucrose in cariogenic dental biofilm formation--new insight. $J$. Dent. Res. 85, 878-87.

20. Rodrigues, L.; Mei, H.C.; Teixeira, J.; Oliveira, R. (2004). Influence of Biosurfactants from Probiotic Bacteria on Formation of Biofilms on Voice Prostheses. Appl. Environ. Microbiol. 70(7), 4408-10.

21. Rodrigues, L.; Moldes, A.; Teixeira, J. A.; Oliveira, R. (2005). Modeling of biosurfactant production by Lactobacillus Strains. http://hdl.handle.net/1822/3463 Universidade do Minho (Portugal) Conference paper.

22. Rodrigues, L.; Banat, I.M.; Teixeira, J.; Oliveria, R. (2006a). Biosurfactants: Potential application in medicine. J. Antimicrob. Chemother. 57, 609-618.

23. Rodrigues, L.; Mei, H.; Banat, I.M.; Teixeria, J.; Oliveria, R. (2006b). Inhibition of microbial adhesion to silicon rubber treated with biosurfactant from Streptococcus thermophilus. FEMS Immunol. Med. Microbiol. 46(1), 107-112.

24. Rodrigues, L.; Teixeira, J.A.; Mei, H.C.; Oliveira, R. (2006c). Physicochemical and functional characterization of a biosurfactant produced by Lactococcus lactis 53. Colloids Surf. B Biointerfaces. 15(49(1)), 79-86.

25. Rodrigous, L.; Teixeira, J.A.; Mei, H.C.; Oliveria, R. (2006d). Isolation and partial characterization of a biosurfactant produced by Streptococcus thermophilus A. Colloid surf. B Biointerfaces. 53, 105-112.

26. Rozen, R.; Bachrach, G.; Bronshteyn, M. (2001). The role of fructans on dental biofilm formation by Streptococcus sobrinus, Streptococcus mutans, Streptococcus gordonii and Actinomyces viscosus. FEMS Microbiol. Lett. 195, 205-10.

27. Schilling, K.M.; Bowen, W.H. (1988). The activity of glucosyltransferase adsorbed onto salivacoated hydroxyapatite. J. Dent. Res. 67, 2-8.

28. Schilling, K.M.; Bowen, W.H. (1992). Glucans synthesized in situ in experimental salivary pellicle function as specific binding sites for Streptococcus mutans. Infect. Immun. 60, 284-95.

29. Schooling, S.R.; Charaf, U.K.; Allison, D.G.; Gilbert, P. (2004). A role for rhamnolipial in biofilm dispertion. Biofilms. 1, 91-99.

30. Santos, A.L.; Jorge, A.O.C.; Santos, S.S.F.; Silva, C.R.G.; Leão, M.V.P. (2009). Influence of probiotics on Candidapresence and $\operatorname{IgA}$ antiCandida in the oral cavity. Braz. J. Microbiol. 40, 960-964.

31. Tam, A.; Shemesh, M.; Wormser, U.; Sintov, A.; Steinberg, D. (2006). Effect of different iodine formulations on the expression and activity of Streptococcus mutans glucosyltransferase and fructosyltransferase in biofilm and planktonic environments. J. Antimicrob. Chemother. 57, 865871.

32. Tamwsada, M.; Kawabata, S. (2004). Synergistic effects of streptococcal glucosyltransferase on adhesive biofilm formation. J. Dent. Res. 83, 8749.

33. Tomitab, Y.; Watanabea, T.; Takeuchi,T.; Nanbua,A.; Shinozaki, N.; kemi, T.; Fukushima, K. (1998). Effects of surfactants on glucosyltransferase production and in vitro sucrose-dependent colonization by Streptococcus mutans. Arch. Oral Bio. 43, 735-40.

34. Tugrul, T.; Cansunar, E. (2005). Detecting surfactant - producing microorganisms by the drop collapse test. World J. Microbiol. Biotechnol. $21,851-853$

35. Uehara, S.; Mondena, K.; Nomotob, K.; Seno, Y.; Kariyama, R.; Kumon, H. (2006). A pilot study evaluating the safety and effectiveness of Lactobacillus vaginal suppositories in patients with recurrent urinary tract infection. Inter. J. Antimicrob. Agents. 28S, S30-34.

36. Vacca-Smith A.M.; Whelehan, M.T.; Berkowitz, R.J.; Feng, C.; Bowen, W.H. (2007). Salivary glucosyltransferase B as a possible marker for caries activity. Caries Res. 41, 445-50.

37. Vater, J.; Kablits, B.; Wild, Ch.; Franke, P.; Mehta, N.; Cameotra, S.S. (2002). Matrix-Assisted Laser Desorption Ionization-Time of Flight MassSpectrometry of Lipopeptide Biosurfactants in Whole Cells and Culture filtrates of Bacillus subtilis C-1 Isolated from Petroleum Sludge. Appl. Environ. Microbiol. 68(12), 6210-19.

38. Velraeds, M.C.; Mei, H.C.; Reid, G.; Busscher, H.J. (1996). Inhibition of Initial adhesion of uropathogenic Enterococcus faecalis by biosurfactants from Lactobacillus Isolates. Appl. Environ. Microbiol. 1996. 62(6), 195863.

39. Walencka, E.; Rozalska, S.; Sadowska, B.; Rozalska, B. (2008). The Influence of Lactobacillus acidophilus-Derived Surfactants on Staphylococcal Adhesion and Biofilm Formation. Folia Microbiol. 53(1), 61-66.

40. Wen, Z.T.; Burne, R.A. (2004). LuxS-mediated signaling in Streptococcus mutans is involved in regulation of acid and oxidative 
Tahmourespour, A. et al. stress tolerance and biofilm formation. J Bacteriol 186(9):2682-2691.

41. Wen, Z.T.; Yates, D.; Ahn,S.J.; Burne, R.A. (2010). Biofilm formation and virulence expression by Streptococcus mutans are altered when grown in dual-species model. BMC Microbiol. 10: 111, doi:10.1186/1471-2180-10-111.

42. Yoshida, A.; Ansai, T.; Takehara, T.; Kuramitsu, H.K. (2005). LuxS-
L. acidophilus-derived biosurfactant effect in S. mutans

based signaling affects Streptococcus mutans biofilm formation. 71 Appl. Environ. Microbiol. (5): 2372-2380.

43. Yoshida, A.; Kuramitsu, H.K. (2002). Multiple Streptococcus mutans genes are involued in biofilm formation. Appl. Environ. Microbiol. 68, 6283-6291. 